\section{Commentary: Follow the resources: Let us count the ways to measure distress in cardiovascular surgery}

\author{
Robert S. D. Higgins, MD, MSHA
}

During my career as a cardiovascular and transplant surgeon, I have been fortunate to visit and train in many different surgical environments, from the United Kingdom to Southern Africa to the Middle East to Asia to Europe, and even socialist countries like Cuba. Each environment, unique as it may be, has strengths and weaknesses in its health care system as it relates to the care of cardiovascular and atherosclerotic heart disease. There is no doubt that the role of surgeons as leaders of multidisciplinary teams has improved outcomes in extraordinary ways around the world.

Prevention and primary care initiatives have an important place in every corner of the world, particularly in underserved and under-resourced areas where sophisticated innovations such as cardiopulmonary bypass, percutaneous valves, and cardiac surgeons are not available. However, in Westernized countries where we have bountiful resources, we should be able to enhance the care and recovery of the majority of those who fall victim to our leading cause of mortality: atherosclerotic heart disease.

Yet, as reported in their article in this issue of the Journal, Mehaffey and colleagues ${ }^{1}$ address disparities in health care and in particular disparities in outcomes of coronary artery bypass grafting (CABG) right here in the United States using an unique metric and methodology applied to the Society of Thoracic Surgeons (STS) adult cardiac database, the Distressed Communities Index (DCI). They highlight the use of a composite measure from the Economic Innovation Group to predict potential comprehensive socioeconomic

\footnotetext{
From the Department of Surgery, Johns Hopkins Medicine, Baltimore, Md Disclosures: The author reported no conflicts of interest.

The Journal policy requires editors and reviewers to disclose conflicts of interest and to decline handling or reviewing manuscripts for which they may have a conflict of interest. The editors and reviewers of this article have no conflicts of interest.

Received for publication May 6, 2020; revisions received May 6, 2020; accepted for publication May 6, 2020; available ahead of print May 16, 2020.

Address for reprints: Robert S. D. Higgins, MD, MSHA, Department of Surgery, Johns Hopkins Medicine, 720 Rutland Ave, Room 759, Baltimore, MD 21205 (E-mail: Robert.higgins@jhmi.edu).

J Thorac Cardiovasc Surg 2020;160:433

$0022-5223 / \$ 36.00$

Copyright (c) 2020 by The American Association for Thoracic Surgery

https://doi.org/10.1016/j.jtcvs.2020.05.011
}

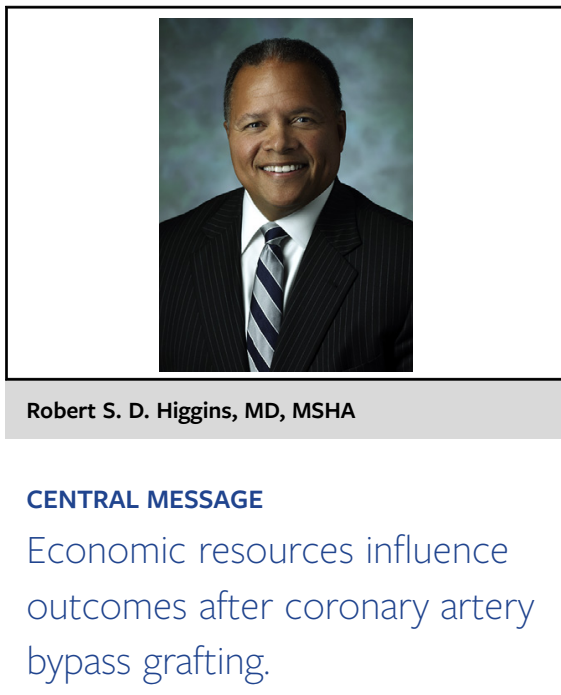

status metrics on a scale of 0 to 100 , including unemployment, education level, poverty rate, median income, business growth, and housing vacancy by ZIP code. Significant correlations with negative outcomes were observed with scores $>75$ in univariate analysis.

Using this socioeconomic metric, the authors apply the DCI to 575,900 patients in the STS database from 2011 to 2014 to correlate and predict outcomes. There was a positive correlation with increased mortality and increased composite morbidity and mortality in distressed communities as measured by these indices. The authors found that $23.8 \%$ of the patients in the database sample were from distressed communities as defined. There were also more females, more minorities, more diabetics, more smokers, more chronic lung disease, and more intraoperative intra-aortic balloon pump uses in this cohort. Operative mortality was higher $(2.3 \%$ vs $1.9 \%)$ in blacks, Hispanics, and Native Americans.

Is this a surprise? And why do we care? In my opinion, no matter how skilled we are as surgeons, what new sophisticated technology we use, and how our guidelines improve the delivery of care, we will fall short on outcomes in those populations that are at greatest risk if we do not improve basic economic conditions in their communities. It is a health care resource issue! We need to measure and incorporate these variables into assessments of outcomes after heart surgery, and particularly CABG, if we want to make a comprehensive difference and to improve the outcome. We cannot improve what we do not measure — but we should follow the money.

\section{Reference}

1. Mehaffey JH, Hawkins RB, Charles EJ, Thibault D, Williams ML, Brennan M, et al. Distressed communities are associated with worse outcomes after coronary artery bypass surgery. J Thorac Cardiovasc Surg. 2020;160:425-32.e9. 